\title{
Analisis Performansi Perutingan Link State Menggunakan Algoritma Djikstra Pada Platform Software Defined Network (SDN)
}

\author{
Abu Riza Sudiyatmoko ${ }^{1}$, Sofia Naning Hertiana ${ }^{2}$, Ridha Muldina Negara ${ }^{3}$ \\ 1,2,3 Prodi S1 Teknik Telekomunikasi, Fakultas Teknik Elektro, Universitas Telkom \\ ${ }_{1,2,3} \mathrm{Jl}$. Telekomunikasi No. 01, Terusan Buah Batu, Bandung, Jawa Barat 40257 \\ Email Korespondensi : sudiyatmoko92@gmail.com
}

Dikirim 13 Februari 2016, Diperbaiki 16 April 2016, Diterima 21 April 2016

\begin{abstract}
Abstrak - Software Defined Network (SDN) merupakan paradigma baru dalam sistem jaringan. Konsep dasar yang diusung oleh SDN adalah pemisahan antara layer control dan forward dalam perangkat yang berbeda. Konsep inilah yang menjadi perbedaan anatar SDN dan jaringan konvensional. Selain itu SDN memberikan konsep network topology virtualisation dan memungkinkan administrator untuk melakukan customize pada control plane. Dengan diterapkannya protokol OpenFlow pada SDN maka terdapat peluang untuk menerapkan perutingan flow based pada jaringan SDN dalam pendistribusian data dari source sampai ke destination. Link state IS-IS merupakan protokol routing yang menggunakan algoritma djikstra untuk menentukan jalur terbaik dalam pendistribusian paket. Dalam penelitian ini dilakukan analisis terhadap implementasi Link State IS-IS pada paltform SDN dengan menggunakan arsitektur RouteFlow. Parameter yang digunakan adalah throughput, delay, jitter dan packet loss serta performansi perangkat controller. Hasil pengujian pada kondisi overload yaitu dengan background traffic $125 \mathrm{Mb}$ nilai packet loss mencapai 1,23\%, nilai throughput 47,6 Mbp/s dan jitter $2.012 \mathrm{~ms}$. Nilai delay terbesar adalah pada topology 11 switch 11 host yaitu berkisar diangka 553 ms. Sedangkan performansi perangkat controller dengan konsumsi memory pada saat menjalankan mengontrol jaringan berkisar diantara 25,638\% sampai $39,04 \%$.
\end{abstract}

Kata kunci - Software Defined Network; OpenFlow; RouteFlow; QoS; Linkstate; IS-IS, Background Traffic

Abstract - Software Defined Network (SDN) is a new paradigm in network system. The basic consept used by SDN is separation beetwen control and forward layer. This concept makes SDN different from todays trditional network. In addition SDN provides network topology virtualization concept and allows administrators to customize the control plane [1]. With the implementation of OpenFlow protocol on SDN, then there is an opportunity to apply a routing in the SDN network from source to destination. Link State IS-IS is a routing protocol use djikstra alghoritm to determine the best path. This research analyse the implementation of Link State IS-IS use RouteFlow architecture. Some parameter are used such as throughput, delay, jitter and packet loss also controller device performance. Results of the analysis showed that based on the above parameters, the IS- IS link state can be implemented on the platform SDN. The result in overload condition is with $125 \mathrm{Mb}$ background traffic, packet loss value reach $1.23 \%$ and throughput is $47.6 \mathrm{MB} / \mathrm{s}$ and jitter is $2.012 \mathrm{~ms}$. The biggest value of delay is happened when network use 11 switch and 11 host topology. In that condition delay value reach $553 \mathrm{~ms}$. While controller device performance consume the memory between $25.638 \%$ until $39.04 \%$ when it run the topologies.

Keywords - Software Defined Network; OpenFlow; RouteFlow; QoS; Linkstate; IS-IS, Background Traffic

\section{PENDAHULUAN}

Kondisi jaringan yang mulai jenuh menjadi alasan mulai banyaknya penelitian dan percobaan platform SDN (Software defined network) yang merupakan salah satu evolusi teknologi jaringan sesuai dengan tuntutan yang berkembang. Dibandingkan dengan jaringan konvensional, Software defined networking (SDN) memberikan kemudahan kepada pengguna dalam mengembangkan aplikasi pengontrol jaringan dengan memisahkan fungsi data plane dari control plane. Pemisahan ini juga memudahkan administrator mengontrol secara langsung paket yang berjalan melalui jaringan [5].

SDN mengusung sebuah paradigma baru dalam jaringan yang awalnya bersifat terdistribusi dan cenderung tertutup menjadi jaringan yang bersifat terpusat, programmable dan terbuka (open source). Dengan demikian memungkinkan seorang peneliti 
atau bahkan administrator untuk mengatur jaringan sesuai dengan kebutuhan. Tidak harus terpaku pada protocol, API dan standar yang ditetapkan oleh para vendor terhadap device/perangkat mereka. SDN memberikan konsep network topology virtualisationdan memungkinkan administrator untuk melakukan customize pada control plane [1].

Dikutip dari white paper yang diterbitkan oleh Open Network Foundation yang berjudul "Software defined networking : The New Norm for Networks" [6], software defined networking (SDN) merupakan sebuah arsitektur jaringan yang sedang berkembang di mana control plane dipisahkan dari forwarding plane dan dapat secara langsung diprogram. Pemindahahan pengendali ,yang sebelumnya terikat pada setiap perangkat jaringan, menjadi dapat diakses oleh perangkat komputasi memungkinkan infrastruktur jaringan dapat diringkas sebagai aplikasi dan layanan jaringan, yang dapat memperlakukan jaringan sebagai sebuah entitas logika atau maya.

Dengan pemisahan fungsi DP (Datapath Plane) dan CP (Control Plane), maka dibutuhkan suatu protokol yang berguna untuk menghubungkan dua elemen tersebut. Saat ini terdapat beberapa protokol yang dikembangkan oleh para pengembang antara lain : OpenFlow dan ForCES. OpenFlow merupakan suatu kerangka kerja yang dikembangkan oleh Universitas Stanford kemudian pada periode selanjutnya dikelola oleh Open Network Foundation (ONF). Sementara itu ForCES dikembangkan oleh grup riset IETF yang mendefinisikan sebuah arsitektur yang terdiri atas protokol transport dan model. ForCES memberikan API yang berguna untuk memisahkan elemen forwarding dan control [8]. Perbedaan mendasar pada jaringan SDN dengan tradisional adalah penempatan fungsi control dan forward. Pada jaringan tradisional fungsi control dan forward ditempatkan pada device yang sama yaitu router. Sedangkan pada jaringan SDN fungsi control ditempatkan pada software terpusat (controller) dan fungsi forward ditempatkan pada suatu perangkat kosong berupa switch (forwarding decive).

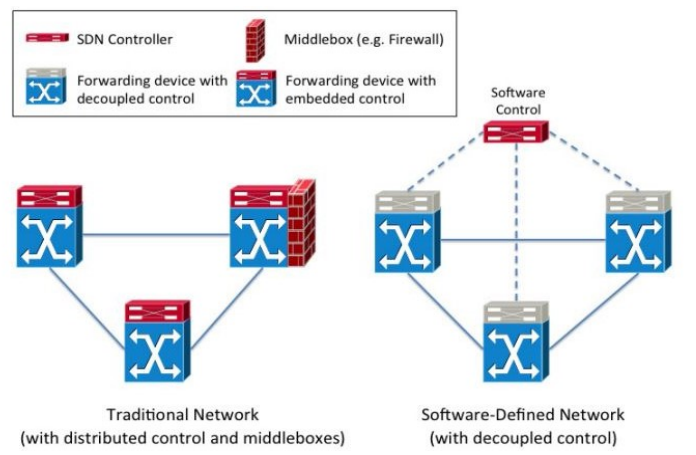

Gambar 1. Perbedaan SDN dengan Jaringan Tradisional [5]
Sementara untuk elemen control, terdapat beberapa jenis controller yang saat ini berkembang, antara lain [7].

- Ryu

- POX

- Opendaylight

Tabel 1. Perbedaan Controllers SDN [7]

\begin{tabular}{|c|c|c|c|}
\hline & Opendaylight & POX & Ryu \\
\hline Bahasa & Java & Python & Python \\
\hline GUI & Tersedia & Tersedia & Tersedia \\
\hline Versi OF & v. 1.0 & v. 1.0 & $\begin{array}{c}\text { v.1.0, v.1.1, } \\
\text { v.1.2, } \\
\text { v.1.3 }\end{array}$ \\
\hline REST API & Tersedia & $\begin{array}{l}\text { Tidak } \\
\text { Tersedia }\end{array}$ & Tersedia \\
\hline Platform & $\begin{array}{l}\text { Linux, MAC, } \\
\text { Windows }\end{array}$ & $\begin{array}{c}\text { Linux, } \\
\text { MAC, } \\
\text { Windows }\end{array}$ & Linux \\
\hline
\end{tabular}

POX dan Ryu merupakan perangkat lunak controller bersumber terbuka yang menggunakan bahasa python sementara Opendaylight menggunakan bahasa java. Opendaylight merupakan proyek yang memiliki dukungan yang cukup luas, proyek ini didukung oleh beberapa perusahaan antara lain : Cisco, Brocade, IBM. [7]

Penelitian ini menggunakan emulator mininet dan RouteFlow untuk merancang topologi jaringan dan sebuah protokol pada kontroler $(P O X)$ dalam jaringan SDN. Penggunaan $P O X$ dilakukan karena merupakan perangkat lunak bersumber terbuka yang menyediakan jalan untuk mengimplementasikan protokol OpenFlow. POX memberikan kemudahan pengguna untuk membuat program yang fungsinya berbeda-beda.

Pada penelitian sebelumnya yang berjudul "On The Resilence of Software Defined Routing Platform" [9][10], telah dilakukan penerapan OSPF pada jaringan SDN dan dihasilkan nilai failover time yang lebih cepat dibandingkan pada jaringan tradisional. Namun belum dilakukan penelitian mengenai pengaruh protokol routing lainnya yaitu Linkstate Intemediate System Intermediate System (IS-IS) pada SDN. Oleh karena itu pada penelitian ini dilakukan analisis apakah protocol routing Linkstate $I S-I S$ dapat diterapkan pada platform SDN berdasarkan parameter throughput, delay, jitter dan packet loss serta performansi perangkat controller.

\section{METODOLOGI PENELITIAN}

\section{A. Software Defined Network (SDN)}

Software Defined Networking (SDN) adalah arsitektur jaringan yang muncul di mana kontrol jaringan dipisahkan dari forwarding dan dapat diprogram secara langsung [2]. Migrasi dari control logic yang digunakan pada networking devices misalkan ethernet switches yang bersifat tightly 
integrated menjadi jaringan yang accessible dan logically centralized controller, sehingga mampu menyediakan jaringan yang fleksibel, programable, vendor-agnostic, cost efficient, dan arsitektur jaringan yang lebih inovatif.

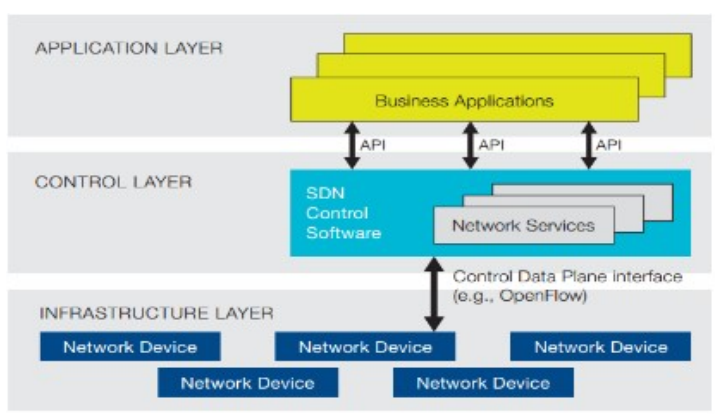

Gambar 2. Arsitektur SDN [2]

Pada Gambar 2, Arsitektur SDN membagi jaringan menjadi 3 layer yaitu application layer, control layer dan insfrastructure/data layer. Application layer merupakan interface terhadap seorang admin atau peneliti dalam mengelola atau mengembangkan jaringan SDN. Control plane berisi suatu controller bersifat terpusat dan based on software. Subordinate hardware dikontrol sepenuhnya oleh controlling plane atau controller dalam melakukan forwarding decission. Semua subordinate terhubung ke controller.

\section{B. Protokol Openflow}

Openflow adalah sebuah control interface yang memungkinkan untuk memprogram switch pada data plan. Sehingga administrator dapat mengontrol secara langsung lalu lintas paket pada forward plan atau data plan melalui interface OpenFlow ini. OpenFlow mendefinisikan infrastruktur flow-based forwarding dan Application Programmatic interface (API) standar yang memungkinkan controller untuk mengarahkan fungsi dari switch melalui saluran yang aman (secure chanel) [2]. Pada Gambar 3 dapat dilihat bahwa controller yang telah diprogram sesuai dengan konfigurasi jaringan yang diinginkan dapat terhubung dengan forward plane. Dimana scure channel ini merupakan perantara bagi controller untuk mengontrol jaringan pada forward plane.

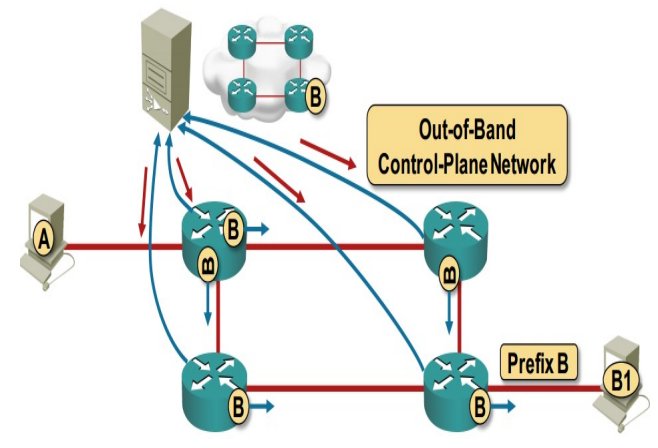

Gambar 3. OpenFlow [11]

\section{Link State Intermediate System Intermediate} System (IS-IS)

Intermediate System Intermediate System adalah sebuah protokol International Organization for Standarization (ISO) untuk Connectionless-mode Network Service (CLNS), protokol network layer dari Operating System Interconnection (OSI). ISIS menggunakan ISO Packet Data Unit (PDU) untuk saling berkomunikasi antar router. Beberapa tipe PDU yang digunakan oleh ISIS adalah Hello PDU, Link State PDU (LSP), dan Sequence Number PDU (SNP). Hello PDU digunakan oleh router yang berdampingan satu sama lain, selain itu router juga dapat menjelajah router baru dalam jaringan serta menetapkan router yang tidak lagi tercapai. Router ISIS saling bertukar informasi melalui Link State PDU (LSP) untu membangun dan mempertahankan data base link state. Adapun cara kerja Link State dalam memilih jalur dapat dilihat pada Gambar 4.

\section{Link State}

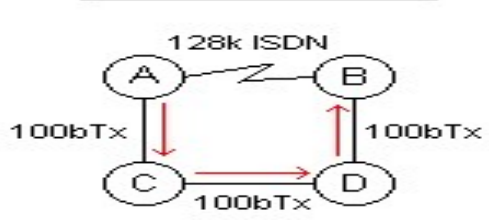

Gambar 4. Routing Link State [12]

\section{Emulator (mininet)}

Emulator yang digunakan dalam penelitian ini adalah mininet. Mininet adalah suatu software emulator yang memungkinkan untuk melakukan prototyping pada jaringan yang luas dengan hanya menggunakan satu mesin [3]. Pada mininet ini dilakukan perancangan jaringan dengan topologi yang diinginkan. Secara sederhana mininet ini berfungsi untuk emulasi pada bagian data path untuk mengetes konfigurasi jaringan SDN. Sedangkan untuk melakukan testing pada mininet dapat dilakukan dengan command "sudo mn". Dengan command ini mininet akan mengemulasikan konfigurasi jaringan SDN yang terdiri dari 1 controller, 1 switch dan 2 host.

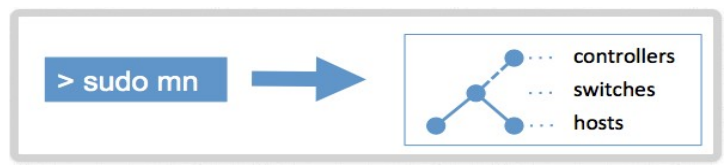

Gambar 5. Single command MININET [3]

\section{E. RouteFlow}

RouteFlow adalah suatu proyek open source untuk menyediakan layanan virtualisasi IP routing pada OpenFlow enabled hardware (switch). Routeflow mengikuti paradigma dari Software Defined Network yaitu berdasarkan pada progmatic and logically network control [4]. RouteFlow terdiri dari Openflow. 
1. Controller Application (RF Proxy).

2. Independent RouteFlow Server (RF Server).

3. Virtual Network Environment (physical infrastructure) dan IP Routing Engine (Quagga).

RouteFlow Controller (RFC) bekerja sebagai aplikasi di atas Network Controller. Network Controller bertanggung jawab dalam interface terhadap switch openflow, berkomunikasi dengan Routeflow dengan API, dan melakukan peninjauan pada topologi jaringan. Core control logic berada pada $R F$-Server yang diberitahu tentang event yang relevan pada jaringan dan mempertahankan yang diperlukan. Untuk setiap OpenFlow switch yang ditemukan, RF-Server menginisiasi atau menetapkannya sebagai satu VM. Pada Gambar 6 dapat dilihat RouteFlow terbagi menjadi 3 layer yaitu Virtual Environment, Controller $(P O X)$ dan Programmable switches. Pada penelitian ini, programmable switches diemulasikan dengan menggunakan mininet.
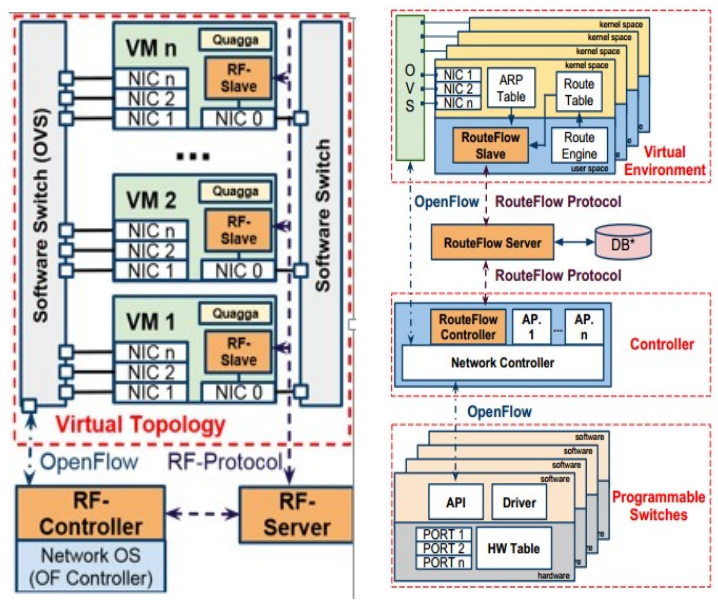

Gambar 6. Arsitektur RouteFlow dan Virtual plane [4]

Sebuah protokol RouteFlow didefinisikan untuk interaksi antara $R F$-Server, $R F$-Controller dan $R F$ Slave. Pesan pada RF-protokol dapat berupa type command atau event dan dapat dilihat sebagai subset sederhana dari pesan protokol OpenFlow ditambah sejumlah pesan baru untuk tujuan konfigurasi dan manajemen $V M / R F$-Slave misalnya untuk menerima atau menolak $V M$, konfigurasi $R F$-Slave dan send update. [3]

\section{HASIL PENELITIAN}

Pada penelitian ini, protokol disimulasikan menggunakan emulator mininet dan menggunakan Pox sebagai kontroler yang telah dienkapsulisasi pada arsitektur RouteFlow. Sistem dimodelkan sebagai sebuah jaringan yang terdiri dari sebuah kontroler dengan sebelas switch dimana setiap port pada switch dan PC memiliki IP masing-masing.

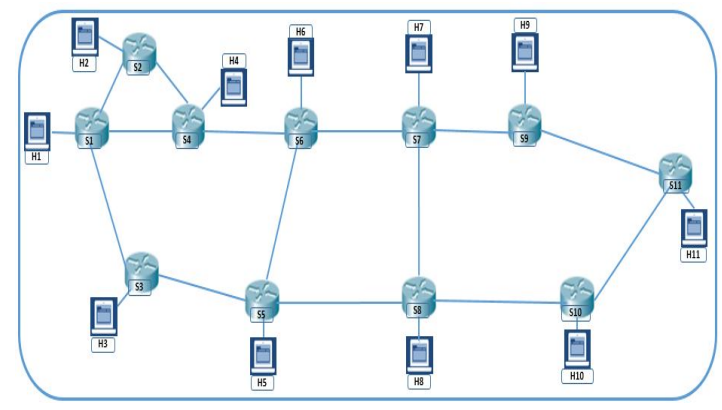

Gambar 7. Topologi Jaringan (Abilene)

Link yang menghubungkan suatu switch dengan switch lain mempunyai cost masing-masing. Cost inilah yang nantinya akan menentukan pemilihan rute dalam pengiriman data dari source sampai dengan destination sesuai dengan routing protocol yang digunakan.

\section{A. Proses Simulasi}

Topologi jaringan dilsimulasikan dalam emulator mininet. Jumlah switch yang digunakan berjumlah 11 (sebelas) buah. Setiap link yang menghubungkan switch mempunyai cost masing-masing yang digunakan sebagai parameter dalam menentukan rute. Setelah itu akan dilakukan pemrograman pada kontroler Pox (RF Proxy pada RouteFlow). Selain tu skenario topologi 7sw $7 \mathrm{~h}$, 9sw 9h juga akan diujikan. Iperf yang digunakan sebagai background traffic untuk membanjiri jaringan adalah $50 \mathrm{Mb}, 75 \mathrm{mb}, 100$ $\mathrm{Mb}$ dan $125 \mathrm{Mb}$.

Tabel 2. Alokasi Background Traffic

\begin{tabular}{cccc}
\hline No & Topologi & $\begin{array}{c}\text { Server- } \\
\text { Client }\end{array}$ & $\begin{array}{c}\text { Background } \\
\text { Traffic }\end{array}$ \\
\hline & & & $50 \mathrm{Mb}$ \\
1. & 7 switch & h1-h7 & $75 \mathrm{Mb}$ \\
& 7 host & & $100 \mathrm{Mb}$ \\
& & & $125 \mathrm{Mb}$ \\
& & & $50 \mathrm{Mb}$ \\
& & & $75 \mathrm{Mb}$ \\
2. & 9 switch & $h 1-h 9$ & $100 \mathrm{Mb}$ \\
& & & $125 \mathrm{Mb}$ \\
& & & $50 \mathrm{Mb}$ \\
& & & $75 \mathrm{Mb}$ \\
3. & 11 switch & $h 1-h 11$ & $100 \mathrm{Mb}$ \\
& 11 host & & $125 \mathrm{Mb}$ \\
\hline
\end{tabular}

\section{B. Parameter Pengujian}

Dalam penelitian ini dilakukan pengujian pengiriman beberapa bit data dalam jaringan SDN. Setelah itu diukur performansi yang dihasilkan pada jaringan SDN dengan menggunakan parameter QoS 
yaitu throughput, delay, jitter, packet loss serta performnce device pada controller.

\section{Perangkat}

\section{Hardware}

Dalam penelitian ini diperlukan beberapa perangkat keras untuk menunjang pengujian terhadap jaringan SDN yang telah dirancang. Perangkat keras yang akan digunakan dalam penelitian ini seperti yang ditunjukkan pada Tabel 3.

Tabel 3. Data Hardware

\begin{tabular}{|c|c|c|}
\hline No & Perangkat & Rincian \\
\hline \multirow{4}{*}{1.} & \multirow{4}{*}{ PC I } & Laptop HP Probook 4420 s \\
\hline & & Processor Intel core i3 \\
\hline & & OS Ubuntu 12.04.4 \\
\hline & & $R A M 4 G B$ \\
\hline \multirow{4}{*}{2.} & \multirow{4}{*}{ PC II } & Desktop Gigabyte 78LMT-S2P \\
\hline & & Processor AMD 8320 \\
\hline & & OS Ubuntu 12.04.4 \\
\hline & & $R A M 8 G B$ \\
\hline 3. & Switch & D-Link DES-1024A \\
\hline 4. & Kabel LAN & $R J 45$ \\
\hline
\end{tabular}

\section{Software}

Software yang dibutuhkan dalam penelitian ini digunakan untuk proses perancangan maupun pengambilan data. Semua software di bawah ini dijalankan dalam OS Ubuntu 12.04.4 baik pada PC I maupun PC II. Adapun software-software tersebut seperti yang ditunjukkan pada Tabel 4.

\begin{tabular}{|c|c|c|c|}
\hline No & Software & Runned in & Function \\
\hline 1. & $\begin{array}{c}\text { RouteFlow } \\
\quad(P O X)\end{array}$ & $P C I$ & Controller \\
\hline 2. & Mininet & $P C I I$ & Emulator data plan \\
\hline 3. & Iperf & $P C I I$ & Background traffic \\
\hline 4. & $D-I T G$ & $P C I I$ & $\begin{array}{l}\text { Analysis throughput, } \\
\text { delay, jitter and } \\
\text { packet loss }\end{array}$ \\
\hline
\end{tabular}

\section{Skenario Pengambilan Data}

Setelah skenario berhasil dilakukan dalam arti host dan switch pada jaringan diatas bisa terkoneksi satu dengan yang lain maka akan dilakukan pengambilan data dari jaringan tersebut. Pengambilan data disini dilakukan dengan menguji performansi pada jaringan dengan menggunakan parameter QoS yaitu throughput, delay, jitter dan packet loss.

Untuk meningkatkan kinerja perangkat, maka akan digunakan perangkat $\mathrm{PC} 2$ sebagai perangkat tambahan. RouteFlow akan dijalankan pada PC1 dengan OS Ubuntu 12.04.4 sedangkan mininet akan dijalankan pada PC2 dengan OS yang sama. Untuk software penguji akan digunakan

Iperf dan D-ITG untuk menguji performansi dari jaringan yang telah dirancang.

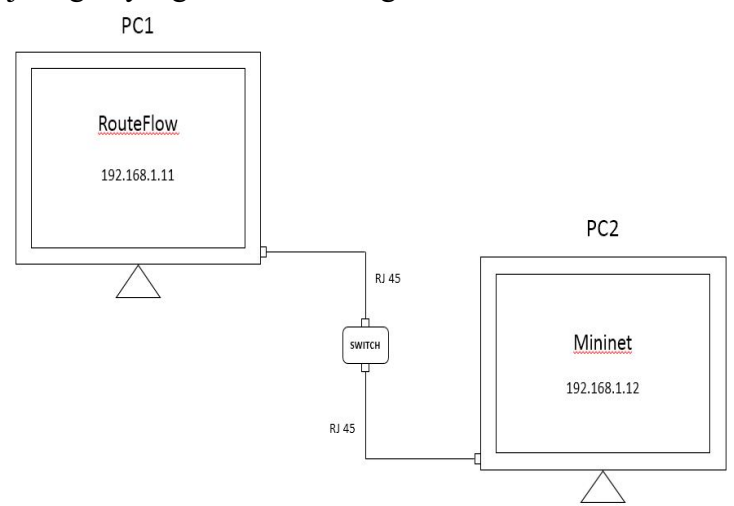

Gambar 8. Skenario Pengambilan Data

Pengambilan data akan menggunakan jumlah switch dan host sebagai variabel peubah. Selain itu juga akan digunakan bandwidth per link dan juga bandwidth background traffic. Ada tiga topologi yang dilakukan yaitu.

1. Menggunakan 7 switch dan 7 host.

2. Menggunakan 9 switch dan 9 host.

3. Menggunakan 11 switch dan 11 host.

Disini akan dilakukan pengamatan pada beberapa link.

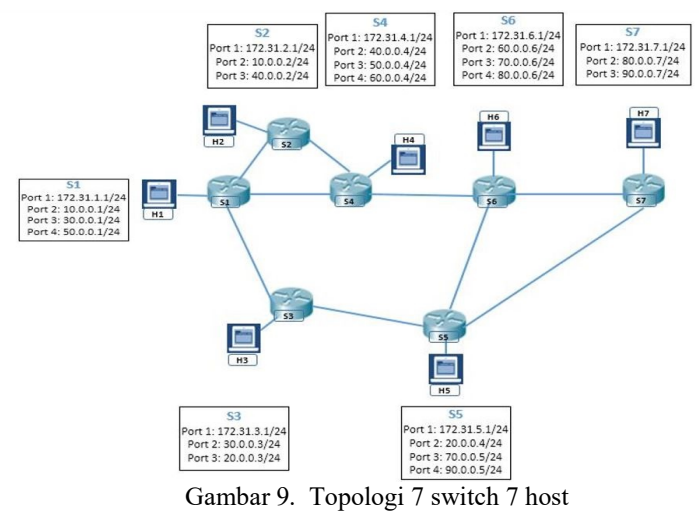

IV. HASIL DAN PEMBAHASAN

Trafik data, video dan VoIP disalurkan melalui server sampai ke client yang telah ditentukan. Dari pengukuran QoS dengan menggunakan D-ITG dapat dilakukan pencatatan dan analisis throughput, delay, jitter dan packet loss serta perfomance device pada controller.

Pengukuran performansi telah dilakukan sebanyak 30 kali setiap skenario (background traffic). Jumlah host dan switch digunakan sebagai variable pengubah. Acuan standar QoS yang digunakan adalah ETSI TS 101 329-2 (European Telecommunications Standard Institute, 2000) tetang Telecommunications and 
Internet Protocol Harmonization Over Network (TIPHON); End to End Quality of Service in TIPHON Systems.

\section{A. Throughput}

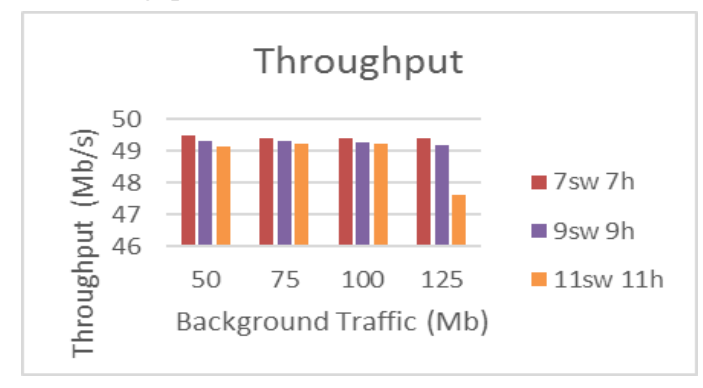

Gambar 10. Throughput

Dari hasil pengukuran hampir semua bandwidth link terpakai. Nilai Throughput semakin kecil seiring dengan semakin kecil seiring dengan semakin besarnya traffic UDP (background traffic) yang membanjiri jaringan. Nilai throughput masuk dalam kategori "sangat bagus" dengan indeks 4 menurut ETSI TS 101 329-2 TIPHON.

\section{B. Analisis Delay}

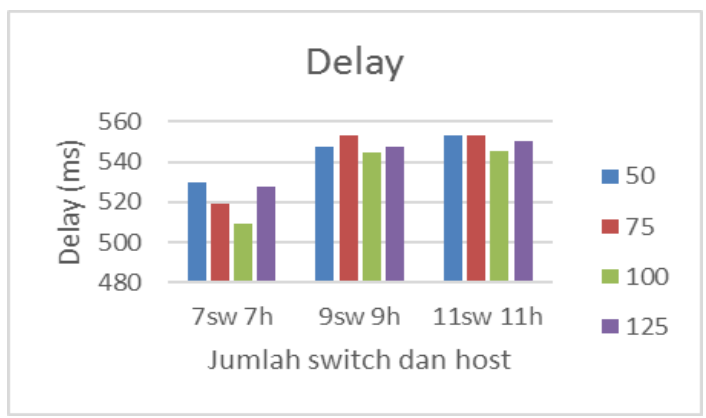

Gambar 11. Delay

Pengukuran dengan background traffic $100 \mathrm{Mb}$ dan $125 \mathrm{Mb}$ menunjukkan nilai delay yang tidak terlalu berbeda dengan pengukuran sebelumnya dengan menggunakan background traffic $50 \mathrm{Mb}$ dan $75 \mathrm{Mb}$. Nilai delay tertinggi terjadi pada topologi 11 host 11 switch yaitu $550,377 \mathrm{~ms}$. Hal ini disebabkan karena delay link sebesar 10 ms sedangkan link yang harus dilalui oleh paket dari h1 sampai h11 merupakan jalur terjauh dibandingkan skenario pengiriman yang lain dalam penelitian ini. Menurut ETSI TS 101 329-2, hasil pengujian untuk semua background traffic masuk dalam kategori "jelek".

\section{Analisis Packet Loss}

Dapat dilihat pada grafik pada Gambar 12 bahwa nilai packet loss semakin menurun seiring semakin besarnya topologi yang diujikan. Nilai packet loss terkecil terjadi pada topologi 11 switch 11 host dengan background traffic $50 \mathrm{Mb}$ yaitu sebesar 1,08\%. Menurut ETSI TS 101 329-2, hasil pengujian dengan background traffic $50 \mathrm{Mb}, 75 \mathrm{Mb}, 100 \mathrm{Mb}$ dan $125 \mathrm{Mb}$ masuk dalam kategori "Sangat Bagus" dengan indeks 4.

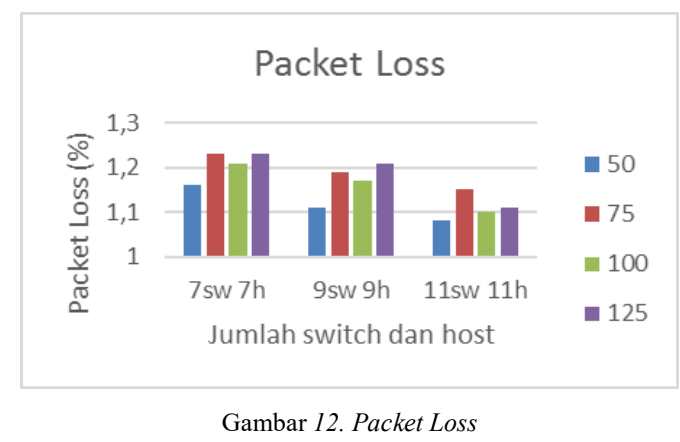

D. Analisis Jitter

Dari hasil pengukuran nilai jitter tidak terlalu berbeda jauh antara satu topologi dengan topologi yang lain. Nilai jitter terbesar tejadi pada saat pengiriman data pada topologi 7 host 7 switch dengan background traffic $125 \mathrm{Mb}$ yaitu sebesar 2,012 ms. Maka dapat disimpulkan bahwa variasi delay dari paket-paket yang ditransmisikan dalam jaringan kecil.

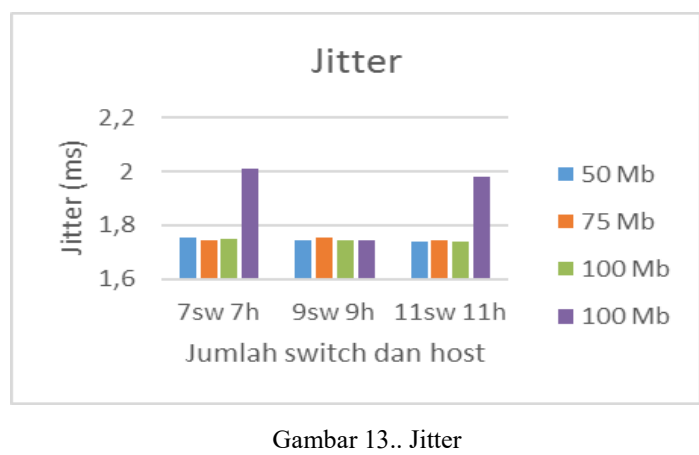

Menurut nilai jitter dari hasil pengukuran masuk dalam kategori "bagus" dengan indeks 3 untuk semua topologi dan background traffic yang digunakan dalam penelitian.

\section{E. Analisis Performansi Perangkat}

Konsumsi memory (RAM) pada controller (PC I) diuji dengan menjalankan 3 skenario topology. Controller memegang peran yang sangat penting dalam jaringan SDN. Maka performansi perangkat controller harus baik untuk mengontrol traffic-traffic pada jaringan SDN.

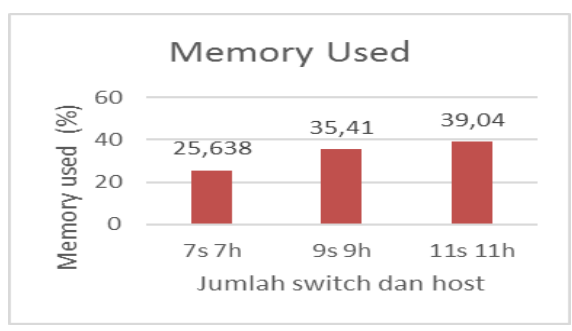

Gambar 14. Memory Used 
Dari Gambar 14 dapat ditarik kesimpulan bahwa semakin besar jaringan dalam hal ini jumlah switch dan host serta link maka resource (memory) yang terpakai pada controller juga akan semakin besar. Maka dari itu performansi perangkat controller sangat menentukan kinerja pada jaringan SDN.

\section{PENUTUP}

\section{A. Kesimpulan}

Dari penelitian yang telah dilakukan dapat ditarik beberapa kesimpulan sebagai berikut.

1) Link state ISIS yang sering digunakan sebagai protocol routing pada jaringan jaringan konvensional dapat diimplementasikan pada platform SDN.

2) Nilai throughput mengalami penurunan seiring dengan semakin besarnya background trafik (UDP).

3) Dengan $\mathrm{BW}$ link $50 \mathrm{Mb}$ dan delay bahan (link) $10 \mathrm{~ms}$ dan dialiri background traffic $50 \mathrm{Mb}, 75$ $\mathrm{Mb}, 100 \mathrm{Mb}, 125 \mathrm{Mb}$ menghasilkan nilai delay data dengan spesifikasi yang telah dijelaskan sebelumnya masuk dalam kategori "jelek" menurut ETSI TS 101 329-2. Semakin besarnya jumlah switch dan link yang dialalui akan menyebabkan semakin besarnya nilai delay.

4) Nilai packet loss ketika dialiri background traffic $50 \mathrm{Mb}, 75 \mathrm{Mb}, 100 \mathrm{Mb}, 125 \mathrm{Mb}$ masuk dalam kategori "sangat bagus". Mayoritas hasil pengujian menunjukkan penurunan nilai packet loss seiring dengan peningkatan jumlah switch.

5) Semakin besar jaringan dalam hal ini jumlah switch dan host serta link pada infrastructure layer maka resource (memory) yang terpakai pada controller juga akan semakin besar.

\section{B. Saran}

Adapun saran yang diberikan untuk menjadi masukan dalam penelitian ini adalah sebagai berikut.

1) Untuk penelitian selanjutnya disarankan untuk memakai RouteFlow yang terbaru agar support untuk semua routing protocol terutama routing protocol yang masih belum banyak dikenal.

2) Khusus untuk Link State IS-IS disarankan untuk menggunakan 2 level untuk penelitian selanjutnya.

\section{DAFTAR PUSTAKA}

[1] Cisco, “SDN," 5 April 2014. [Online]. Available: https://www.cisco.com/web/ANZ/ciscolive/attend/hot_topics/sdn.html. [Accessed 5 January 2015].

[2] G. Patel, A.S. Athreya, and S. Erukulla., "OpenFlow based Dynamic Load Balanced Switching, “ COEN 233, Project Report, 2013.
[3] I. Pepelnjak, OpenFlow and SDN: Hype, Useful Tools or Panacea?,IP Space, 2013.

[4] I. Sofana, Cisco CCNP dan Jaringan Komputer, Bandung: Informatika, 2012.

[5] M. Team, Mininet An Instant Virtual Network on your Laptop (or other PC), [Online]. Available: http://mininet.org/. [Accessed 5 Maret 2014].

[6] Nascimento, Marcelo R., The RouteFlow Approach Leveraging Software-Defined, Research and Development Center (CPqD), 2011.

[7] Open Network Foundation.(2012). SoftwareDefined Networking: The New Norm for Networks.

[8] S. Azodolmolky, Software Defined Networking with OpenFlow, Birmingham: Packt Publishing, 2013.

[9] The Network and Management Architecture Group (NAM), University of Patras, Greece, "Software defined networking (SDN), [Online]. Available:

http://nam.ece.upatra.gr/index.php?q=node/59

[10] Tomovic, S., Radonjic, M., \& Radusinovic, I. (n.d.). Quagga Routing Platform: Application and Performance. University of Montenegro, Faculty of Electrical Engineering, Montenegro.

[11] Tulloh. Rohmat, Negara M. Ridha, Hidayat. Arif, Simulasi Virtual Local Area Network (VLAN) Berbasis Software Defined Network (SDN) Menggunakan POX Controller, Jurnal Infotel, 2015.

[12] Zeng, P., Nguyen, K., Shen, Y., \& Yamada, S. (2014). On The Resilence of Software Defined Routing Platform. APNOMS. 